\title{
Lung Changes on Chest CT During 2019 Novel Coronavirus (COVID-19) Pneumonia
}

\author{
Akın Çinkooğlu (i), Selen Bayraktaroğlu (1), Recep Savaş(1) \\ Department of Radiology, Ege University School of Medicine, İzmir, Turkey
}

Cite this article as: Çinkooğlu A, Bayraktaroğlu S, Savaş R. Lung Changes on Chest CT During 2019 Novel Coronavirus (COVID-19) Pneumonia. Eur J Breast Health 2020; 16(2): 89-90.

The novel Coronavirus, currently named as SARS-COV-2, was first identified in Wuhan, in December 2019. Within a few months, the virus has spread from China to worldwide. On March 11, 2020, the World Health Organization (WHO) declared this global outbreak as a pandemic (1). In Turkey, the first case was reported on March 11. The number of COVID-19 positive cases increased meanwhile and by March 30, 10827 cases have been reported (2).

The clinical diagnosis of COVID-19 is confirmed by the real-time reverse-transcription-polymerase-chain-reaction (RT-PCR) assay through combined oropharyngeal and nasopharyngeal swab samples. RT-PCR assay is referred to as the reference standard for diagnosis. The total positive rate of RT-PCR assay was reported to be 30-60\% at the period of initial presentation (3). This high false-negative rate and limited availability of RT-PCR tests during the outbreak are the major drawbacks of this test. Ai et al. (4), has mentioned about the complementary role of noncontrast Chest Computed Tomography (CT) in patients with false-negative RT-PCR test results. Regarding RT-PCR as the reference, they reported the sensitivity of Chest CT imaging as 97\%. Similarly, Fang et al. (5) reported the greater sensitivity of Chest CT (98\%) compared with RT-PCR (71\%). In a meta-analysis, the pooled positive rate of thin-slice CT imaging was $90.35 \%$ (6). These findings support that CT examination may help diagnosis especially in cases with high clinical suspicion and negative RT-PCR test results at initial presentation. This point of view seems reasonable considering the importance of early recognition of the disease can facilitate patient isolation and treatment.

While emphasizing the importance of CT findings, it must be mentioned that chest radiography is typically the first-line imaging modality. However, the most common infiltration pattern is ground-glass opacity (GGO) and it may be overlooked on chest x-rays. Correspondingly, there are studies showing the lower sensitivity of chest x-ray compared with that of CT (7).

To date, several studies characterizing the CT imaging findings have been published. Ye et al. (8), in their review article, revealed the diversity of the imaging findings seen on chest CT. Some of these CT findings such as infiltration and distribution patterns are more prominent and provide insight regarding the diagnosis. For instance, the distribution pattern of the lesions is of great importance at the characterization of COVID-19 pneumonia. Most of the patients have bilateral, peripheral and subpleural lung involvement (9-11). Lower lobes are the most frequently affected areas and additionally, some studies showed that lesions tend to be placed in the dorsal part of the lungs $(8,12)$. GGO is the most common and early detected infiltration pattern $(9-11,13,14)$. GGOs may be patchy or rounded. Pure GGO, GGO with reticular and/or interlobular septal thickening (crazy-paving pattern), and GGO with consolidation are the different forms of infiltration. Song et al. investigated CT findings of 51 patients and reported that GGO with reticular and/ or interlobular septal thickening was the second most common (75\%) form of infiltration following pure GGO (77\%). GGO with consolidation (59\%) and complete consolidation were relatively less common (55\%) findings in the same study and these two patterns were considered as an indication of disease progression (9). Another combination of GGO and consolidation known as "reverse halo sign", defined as central GGO surrounded by ring-like consolidation, were reported in some studies (7). Air bronchograms, discrete GGO nodules and solid nodules (with or without halo sign), and subpleural lines are other featured parenchymal CT findings (7, 8, $12,15,16$ ). Airway involvement (dilatation, wall thickening), vascular enlargement, pleural thickening are relatively rare, but possible imaging findings of the disease (8). Although lymph node enlargement, cavitation, pericardial and pleural effusion are uncommon 
findings, they may be seen with disease progression (17). Li et al. (18) investigated CT features of 25 patients in severe condition and revealed higher incidences of lymph node enlargement, pericardial effusion and pleural effusion than the ordinary patients.

CT imaging not only helps in the diagnosis of the disease but also gives information about comorbid situations such as the presence of emphysema, fibrosis. Regarding the clinical findings, disease progression and treatment response can be monitored with serial CT examinations. Lung abnormalities that are detected in patients with COVID-19, peak around 6-11 days after the onset of the symptoms (19). The improvement of CT findings appear around 14 days, the absorption stage may extend beyond 26 days (20).

Radiologists must be aware of complications, particularly, acute respiratory distress syndrome (ARDS). In their cohort study, Wu et al. (21) reported that 84 of 201 patients (41.8\%) have developed ARDS and of those 44 patients $(52.4 \%)$ have died. Given the role of imaging in the diagnosis and follow-up of ARDS, the knowledge of the imaging findings is crucial.

Within this period, our hospital serves as a quarantine hospital. All of the departments including emergency, microbiology, radiology, chest and infectious diseases work together in diagnosis and follow-up. The most common symptoms of patients are fever and cough. Most of the patients undergo both RT-PCR test sampling and chest CT examination. At the early stages of the disease (1-4 days), on chest CT images, we commonly see GGOs distributed mostly bilateral and peripheral with lower lobe predilection. Later on, GGO with consolidation or septal thickening (crazy paving pattern), pure consolidation, and subpleural lines are seen as additional imaging findings. We rarely observe unilateral, central distribution, and isolated upper lobe infiltration as an initial finding. Pleural and pericardial effusion, mediastinal and hilar lymphadenopathies are uncommon imaging findings.

\section{Conclusion}

Diagnosis, treatment, and follow-up of COVID-19 pneumonia is a teamwork. Radiologists have an important role, since imaging plays a critical role in initial diagnosis as well as in assessment of disease severity and progression.

\section{References}

1. World Health Organization. 2020. Coronavirus disease 2019 (COVID-19) situation report-51. World Health Organization, Geneva. Available from: https://www.who.int/docs/default-source/coronaviruse/situation-reports/20200311-sitrep-51-covid-19.pdf?sfvrsn=1ba62e57_10.

2. Turkish Government, Ministery of Health. 2020. Available from: https:// covid19.saglik.gov.tr/.

3. Yang Y, Yang M, Shen C, Wang F, Yuan J, Li J, et al. Evaluating the accuracy of different respiratory specimens in the laboratory diagnosis and monitoring the viral shedding of 2019-nCoV infections. MedRxiv 2020; DOI: 10.1101/2020.02.11.20021493. [CrossRef]

4. Ai T, Yang Z, Hou H, Zhan C, Chen C, Lv W, et al. Correlation of Chest CT and RT-PCR Testing in Coronavirus Disease 2019 (COVID-19) in China: A Report of 1014 Cases. Radiology 2020; DOI: 10.1148/radiol.2020200642. [CrossRef]
5. Fang Y, Zhang H, Xie J, Lin M, Ying L, Pang P, et al. Sensitivity of chest CT for COVID-19: comparison to RT-PCR. Radiology 2020; DOI: 10.1148/radiol.2020200432. [CrossRef]

6. Bao C, Liu X, Zhang H, Li Y, Liu J. COVID-19 Computed Tomography Findings: A Systematic Review and Meta-Analysis. J Am Coll Radiol 2020; DOI: https://doi.org/10.1016/j.jacr.2020.03.006. [CrossRef]

7. Yoon SH, Lee KH, Kim JY, Lee YK, Ko H, Kim KH, et al. Chest Radiographic and CT Findings of the 2019 Novel Coronavirus Disease (COVID-19): Analysis of Nine Patients Treated in Korea. Korean J Radiol 2020; 21: 494-500. [CrossRef]

8. Ye Z, Zhang Y, Wang Y, Huang Z, Song B. Chest CT manifestations of new coronavirus disease 2019 (COVID-19): a pictorial review. Eur Radiol 2020; DOI: 10.1007/s00330-020-06801-0. [CrossRef]

9. Song F, Shi N, Shan F, Zhang Z, Shen J, Lu H, et al. Emerging 2019 Novel Coronavirus (2019-nCoV) Pneumonia. Radiology 2020; 295: 210-217. [CrossRef]

10. Shi H, Han X, Jiang N, Cao Y, Alwalid O, Gu J, et al. Radiological findings from 81 patients with COVID-19 pneumonia in Wuhan, China: a descriptive study. Lancet Infect Dis 2020; 20: 425-434. [CrossRef]

11. Zhao W, Zhong Z, Xie X, Yu Q, Liu J. Relation Between Chest CT Findings and Clinical Conditions of Coronavirus Disease (COVID-19) Pneumonia: A Multicenter Study. AJR Am J Roentgenol 2020; 1-6. [CrossRef]

12. Wu J, Wu X, Zeng W, Guo D, Fang Z, Chen L, et al. Chest CT Findings in Patients with Corona Virus Disease 2019 and its Relationship with Clinical Features. Invest Radiol 2020; DOI: 10.1097/ RLI.0000000000000670. [CrossRef]

13. Chung M, Bernheim A, Mei X, Zhang N, Huang M, Zeng X, et al. CT Imaging Features of 2019 Novel Coronavirus (2019-nCoV). Radiology 2020; 295: 202-207. [CrossRef]

14. Guan WJ, Ni ZY, Hu Y, Liang WH, Ou CQ, He JX, et al. Clinical Characteristics of Coronavirus Disease 2019 in China. N Engl J Med 2020; DOI: 10.1056/NEJMoa2002032. [CrossRef]

15. Pan F, Ye T, Sun P, Gui S, Liang B, Li L, et al. Time Course of Lung Changes On Chest CT During Recovery From 2019 Novel Coronavirus (COVID-19) Pneumonia. Radiology 2020; DOI: 10.1148/radiol.2020200370. [CrossRef]

16. Pan Y, Guan H, Zhou S, Wang Y, Li Q, Zhu T, et al. Initial CT findings and temporal changes in patients with the novel coronavirus pneumonia (2019-nCoV): a study of 63 patients in Wuhan, China. Eur Radiol 2020; DOI: 10.1007/s00330-020-06731-x. (PMID: 32055945) [CrossRef]

17. Salehi S, Abedi A, Balakrishnan S, Gholamrezanezhad A. Coronavirus Disease 2019 (COVID-19): A Systematic Review of Imaging Findings in 919 Patients [published online ahead of print, 2020 Mar 14]. AJR Am J Roentgenol 2020; 1-7. [CrossRef]

18. Li K, Wu J, Wu F, Guo D, Chen L, Fang Z, et al. The Clinical and Chest CT Features Associated with Severe and Critical COVID-19 Pneumonia. Invest Radiol 2020; DOI: 10.1097/RLI.0000000000000672. [CrossRef]

19. Wang Y, Dong C, Hu Y, Li C, Ren Q, Zhang X, et al. Temporal Changes of CT Findings in 90 Patients with COVID-19 Pneumonia: A Longitudinal Study. Radiology 2020 DOI: 10.1148/radiol.2020200843. [CrossRef]

20. Pan F, Ye T, Sun P, Gui S, Liang B, Li L, et al. Time Course of Lung Changes On Chest CT During Recovery From 2019 Novel Coronavirus (COVID-19) Pneumonia. Radiology 2020; DOI: 10.1148/radiol.2020200370. [CrossRef]

21. Wu C, Chen X, Cai Y, Xia J, Zhou X, Xu S, et al. Risk Factors Associated With Acute Respiratory Distress Syndrome and Death in Patients With Coronavirus Disease 2019 Pneumonia in Wuhan, China. JAMA Intern Med 2020; DOI: 10.1001/jamainternmed.2020.0994. (PMID: 32167524) [CrossRef] 